\title{
Determination of expression profile of p53 gene in different grades of breast cancer tissues by real time PCR
}

\author{
Haleema Sadia ${ }^{1,2}$, Munir Ahmad Bhinder ${ }^{3}$, Asma Irshad ${ }^{4}$, Beenish Zahid ${ }^{5}$, Rais Ahmed 6 , \\ Sana Ashiq ${ }^{2}$, Kausar Malik ${ }^{7}$, Muhammad Riaz ${ }^{8}$, Tariq Nadeem 7 , Kanwal Ashiq ${ }^{9}$, Ali Akbar ${ }^{10}$
}

1. Department of Biotechnology, Balochistan University of Information Technology, Engineering and Management Sciences, Quetta, Pakistan.

2. Center for Applied Molecular Biology, University of the Punjab, Lahore, Pakistan.

3. Department of Human Genetics and Molecular Biology, University of Health Sciences, Lahore, Pakistan.

4. Department of Life Sciences, University of Management and Technology (UMT) Lahore, Pakistan.

5. Department of Pathology, UVAS, Narowal, Pakistan.

6. Department of Microbiology, Cholistan University of Veterinary and Animal Sciences CUVAS, Cholistan, Pakistan.

7. National Centre of Excellence in Molecular Biology, University of the Punjab, Lahore, Pakistan

8. Department of Allied Health Sciences, University of Sargodha, Sargodha Pakistan.

9. Faculty of Pharmaceutical Sciences, Superior University Lahore, Pakistan.

10. Department of Microbiology, University of Balochistan, Pakistan.

\begin{abstract}
Background: Pakistan has a high incidence of breast cancer in Asia, where annually 16,232 deaths are reported. There are many exogenous and endogenous risk factors that affect the tumor suppressor genes and oncogenes. The p53 gene is a tumor suppressor gene and it has a role to protect the whole genome from external and internal stresses, which causes damages to the genome.

Objective: The aim of the current study was to investigate the p53 gene expression by using the real-time PCR technique in different grades of breast cancer as compared to the normal tissue.

Methods: Fresh Modified Radical Mastectomy (MRM) samples (grade1-grade3) were collected from different hospitals of the Lahore. The project was approved by an ethical review committee of Jinnah Hospital, Lahore. And before sampling an informed consent was obtained from patients and clinicians. RNA from fresh biopsies was extracted by Qiagen extraction kit and cDNA was formed. Real time PCR performed by using SYBR green master mix (ABI) and the data was evaluated by using Livak method. Statistical analysis was done by using Microsoft Excel.

Results: There was an abnormal gene expression of $\mathrm{p} 53$ in all grades of the breast tumors. Non-significant $(\mathrm{p}>0.05)$ difference of down and up regulation of p53 in different grades of breast tumor was found. However, as a whole up-regulation was more than down-regulation with significant difference $(\mathrm{p}<0.0011)$.

Conclusion: The abnormal expression of p53 shows that there are some genetic and epigenetic factors which are the primal cause of an abnormal gene expression. It is recommended that perform next generation sequencing (NGS) of the gene to find out the mutations causing the abnormal behavior of p53 gene.

Keywords: Breast cancer, up-regulation, down-regulation, real-time PCR, Punjab, Pakistan, p53 gene.

DOI: https://dx.doi.org/10.4314/ahs.v20i3.32

Cite as: Sadia H, Bhinder MA, Irshad A, Zabid B, Ahmed R, Ashiq S, et al. Determination of expression profile of p53 gene in different grades of breast cancer tissues by real time PCR. Afri Health Sci. 2020;20(3): 1273-1282. https:// dx.doi.org/ 10.4314/ abs.v20i3.32
\end{abstract}

\begin{tabular}{l} 
Corresponding author: \\
Haleema Sadia, \\
Department of Biotechnology, \\
Balochistan University of Information \\
Technology, Engineering and Management \\
Sciences, Quetta, Pakistan. \\
and \\
Center for Applied Molecular Biology, \\
University of the Punjab, Lahore, Pakistan. \\
Email: sadiahaleema377@gmail.com \\
\hline
\end{tabular}

Introduction

Cancer is a disease that occurs due to changes in the DNA sequence of the cells genome and it is responsible for one in eight deaths globally ${ }^{1}$. Breast cancer is one of the major types of malignant neoplasm and its incidence is quite high in Asia. The type of tissue cancer which mainly involves inner layers of milk glands or lobules and ducts is called as breast cancer ${ }^{2}$. It is a heterogeneous disease comprising a number of distinct subtypes with varied clinical outcome and behavior ${ }^{3}$.

(C) 2020 Sadia H et al. Licensee African Health Sciences. This is an Open Access article distributed under the terms of the Creative commons Attribution License (https://creativecommons.org/licenses/BY/4.0), which permits unrestricted use, distribution, and reproduction in any medium, provided the original work is properly cited. 
Broadly, it is divided into three major types non-invasive, invasive and others that are responsible for $1-4 \%$ of breast cancer include Paget's disease of the nipple 4 . It is classified into three major grades included: Grade I which is well differentiated, Grade II is differentiated intermediary and Grade III which is poorly differentiated. According to the number of affected lymph nodes it is classified into Grade I with no lymph nodes affection, Grade II in which one to three lymph nodes are affected and when $\geq 4$ lymph nodes it is the Grade III ${ }^{5}$. Every year, one million women reported to diagnose with breast cancer ${ }^{6}$. Around the globe, it is the second leading cause of mortality among women aged 45-55 years ${ }^{2}$ and more than 1,000,000 breast cancer cases in females are reported annually ${ }^{7}$. Its incidence varies as it is being highest in North America and Western Europe, while it is lowest in Asia and Africa ${ }^{8}$. Early detection by using screening mammography and multimodality treatment has abridged the mortality due to this disease in western countries but in developing countries, it is still continuing to have a high prevalence? In Pakistan, the ratio of developing breast cancer is rising at an alarming rate and it is $38.5 \%$ of other types of cancer ${ }^{4}$.

During 1995-1997, the incidence of breast cancer has reported $33.1 \%$ in the population of Karachi south district ${ }^{6}$. Breast carcinogenesis involves several genetic and environmental factors. However, as compared to the racial and genetic factors the environmental factors are more readily controlled ${ }^{10}$. The other risk factors are: diet, especially which is rich in fat, smoking, family history of breast cancer, depression and stress ${ }^{6}$. The appearance of lumps, compactness of dimple, redness, and soreness are the most common symptoms which are associated with the onset of breast cancer ${ }^{4}$. Genetic predisposition caused by a mutation in autosomal dominant genes is responsible for $5-10 \%$ of all breast malignancies. The genetic variation which is involved in the development of breast tumors is of two broad types; one is loss of function mutation in tumor suppressor gene which leads towards the uncontrolled cell growth and division, disturbance of the checkpoints of cell cycle and DNA mechanism of repair failure, while the second is in the proto-oncogene gain of function mutation. Before the age of 70 years, there is a $70 \%$ risk of breast cancer development in women's with inherited loss of function mutation ${ }^{10}$. There are several genes in which the mutations can affect the body differently and thus lead to the development of various types of breast cancer. The genes which are mainly involved in breast cancer includes BRCA1 and BRCA2 which cause $90 \%$ of breast cancer while other are HER2, PIK3, and deregulation of expression of three genes MDM2, RB and TPK53 can play a significant role in therapeutic vibes of breast cancer ${ }^{4}$. A multifunctional tetrameric transcription factor which is known as the tumor suppressor gene TP53 is the maintaining of genome stability is the major functions of wild-type p5 which plays a crucial role in the senescence, control of cell cycle progression, DNA repair and apoptosis ${ }^{11}$. The first tumor suppressor gene is the p53 that is described in 1979 and initially, it is believed to be an oncogene ${ }^{12}$. Human p53 is $20 \mathrm{~kb}$ gene located on $17 \mathrm{p} 13.1$ it is a nuclear phosphoprotein of molecular weight $53 \mathrm{kDa}$, which consists upon 10 introns and 11 exons with more than 200 single nucleotide polymorphisms (SNPs) been identified in both non-coding and coding regions and the common polymorphisms in this gene showed association with increased risk which is reported by many published studies ${ }^{11}$.

The use of real-time PCR in clinical testing plays a crucial role as it can provide the information related to small alterations such as point mutation, gene expression, and gene loss or amplification and it also plays a useful job in the analysis of cancer markers ${ }^{13}$. It is a high-throughput technology, which is used for sensitive detection and accurate quantitation of the gene expression levels $^{14}$. The mutant $\mathrm{p} 53$ results in genetically unstable cells as it is no longer able to control cell proliferation and resulting in inefficient DNA repair which may lead to the neoplasia due to genomic damage persistence ${ }^{15}$. In invasive breast cancer, molecular genetic profile of alterations in $\mathrm{p} 53$ is well characterized in contrast to ductal carcinoma in situ. As compared to molecular biology screening techniques immunohistochemical analysis of p53 expression is mostly done in ductal carcinoma in situ. Molecular biology screening techniques are used in a very few studies and of these the only three studies conducted for $\mathrm{p} 53$ sequence alterations in the ductal carcinoma in situ cohorts by using constant density gel electrophoresis (CDGE) or single-strand conformational polymorphism (SSCP) which then confirmed by using DNA sequence analysis of all potential SSCP/ CDGE altered mobility patterns ${ }^{16}$. In the carcinogenesis process of breast, the important role of p53 alterations is reported in several studies. It is documented that mutations in p53 is around zero in low-grade ductal carcinoma in situ (DCIS) to $30-40 \%$ in high grade ${ }^{15}$. To the best of our knowledge, there is a lack of data on 
p53 gene expression in breast cancer by using real-time PCR, thus the purpose of the present study was to investigate the p53 gene expression in different grades of breast cancer as compared to the normal tissue by using the real-time PCR technique.

\section{Materials and methods}

\section{Sample collection}

Thirty (30) fresh Modified Radical Mastectomy samples were collected from different hospitals of Lahore, Punjab. Each sample was collected in two tubes, one tube having RNAlater or Ethanol and the other tube having $10 \%$ formalin. All samples were stored at $-20^{\circ} \mathrm{C}$ before RNA extraction. This project was funded by the Higher education commission (HEC), Pakistan and ethical approval was taken from the Jinnah Hospital, Lahore and ethical consent was taken from patients.
Histopathological analysis of breast tumor tissues The tissues present in 10\% formalin were sent to histopathological labs of Fatima Memorial Hospital, Lahore for haematoxylin and eosin staining.

\section{Gene expression of p53 gene by Real Time PCR}

RNA was extracted by Qiagen extraction kit and concentration was measured by qubit ${ }^{\circledR} 3.0$ fluorimeter (in vitrogen) was used along with qubit ${ }^{\circledR}$ RNA assay kit (Lot \# 1007806).

\section{Complementary DNA (cDNA) synthesis}

RNA concentrations of all samples were equalized $(100 \mathrm{ng} / \mu \mathrm{L})$. Complementary DNA (cDNA) was synthesized from each RNA sample by using the enzynomics DNA Synthesis kit (MB125).

The reagents and techniques are described in Table 1 and the cycling conditions are shown in Figure 1.

Table 1. Reagents and techniques for the complementary DNA synthesis

\begin{tabular}{llll}
\hline $\begin{array}{l}1^{\text {t }} \text { Step } \\
\text { Reagents }\end{array}$ & Volumes & $\begin{array}{l}\mathbf{2}^{\text {nd }} \text { Step } \\
\text { Reagents }\end{array}$ & Volumes \\
\hline RNA & $2 \mu \mathrm{L}(100 \mathrm{ng} / \mu \mathrm{L})$ & $10 \mathrm{X}$ RT Buffer & $2 \mu \mathrm{L}$ \\
Oligo-Dt & $1 \mu \mathrm{L}$ & Reverse & $1 \mu \mathrm{L}$ \\
& & Transcriptase & \\
Random Hexamers & $1 \mu \mathrm{L}$ & dNTPs & $2 \mu \mathrm{L}$ \\
& & RNase Inhibitor & $0.5 \mu \mathrm{L}$ \\
$70^{\circ} \mathrm{C}$. for 10 Minutes & & DEPC water & $10.5 \mu \mathrm{L}$ \\
& & Total & $20 \mu \mathrm{L}$ \\
\hline
\end{tabular}

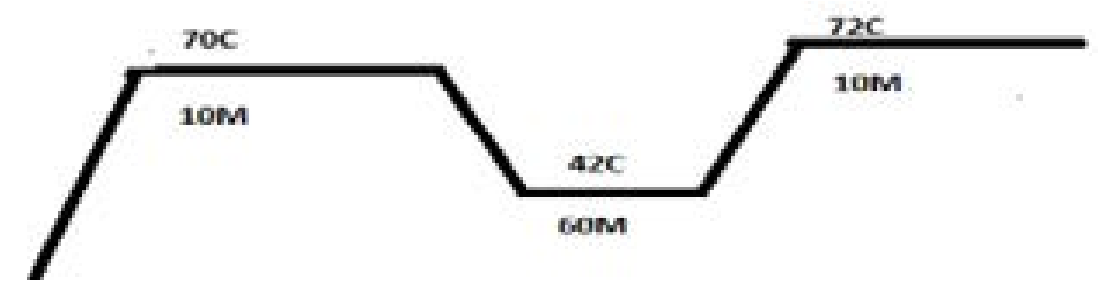

Figure 1. Complementary DNA (cDNA) incubation temperature and timings on rotorgene Q 
Primer designing

Primers were designed by primer 3 software covering the 100-150bp for gene expression studies of p53 gene (Table 2).

Table 2. $p 53$ and $\beta$ actin (housekeeping gene) gene primers for Real Time PCR

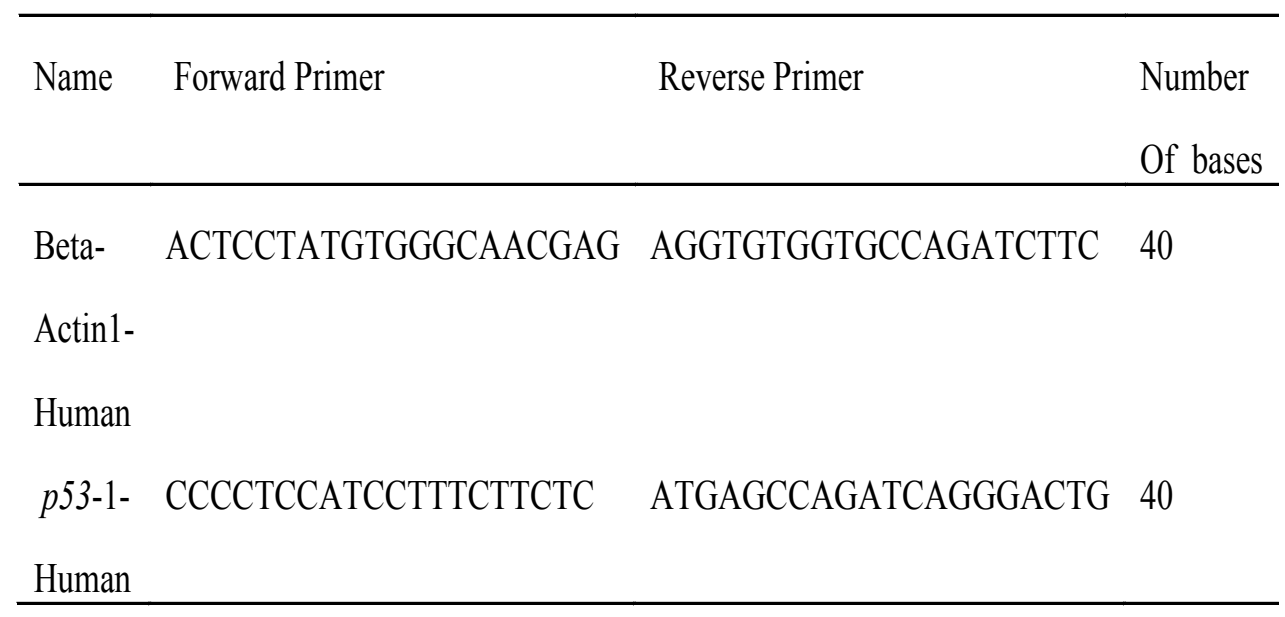

\section{Real-Time PCR amplification}

For real time PCR SYBR green master mixture was used (Thermo scientific USA).

The beta actin gene was used as a reference gene while p53 gene was the target gene. The reaction was performed in triplicates. The rotorgene real time PCR machine was used. The reagents and recipe is given below in Table 3 and Figure 2.

Table 3. Reagents and recipe for the PCR Reaction

\begin{tabular}{ll}
\hline Reagents & Volume per 25 $\mu$ l reaction \\
\hline SYBR Green & $12.5 \mu \mathrm{l}$ \\
Forward Primer & $1 \mu \mathrm{l}$ \\
Reverse Primer & $1 \mu \mathrm{l}$ \\
Water & $8.5 \mu \mathrm{l}$ \\
Template (cDNA) & $2 \mu \mathrm{l}$ \\
\hline
\end{tabular}

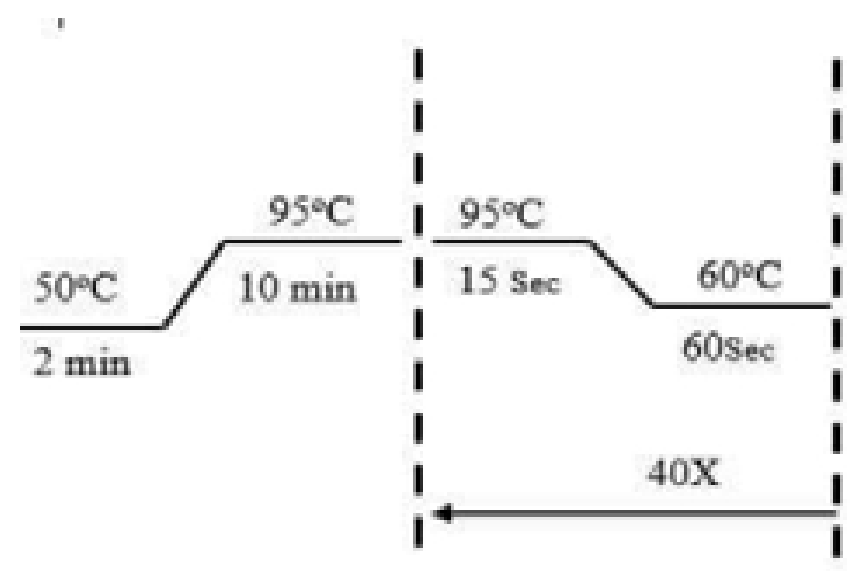

Figure 2. PCR cycling condition for Real-Time PCR of $p 53$ gene 
Gene expression folds change calculation

For expression data, the target gene $\mathrm{p} 53 \mathrm{Ct}$ was normalized with the $\beta$-actin $\mathrm{Ct}$. The mean of $\mathrm{Ct}$ values of $\mathrm{p} 53$ gene and mean of $\mathrm{Ct}$ values of beta-actin gene were compared. The calculation was based on $\Delta \Delta \mathrm{Ct}$ or Livak method (Livak and Schmittgen, 2001). The formulas of livak method were added in the excel sheet and fold change values of all tumor samples were calculated as compared to reference gene and also as compared to normal adjacent breast sample.

\section{Statistical analysis}

Microsoft Excel was used for statistical analysis. T-test was used for the statistical analysis by the using excel chart and 95\% Confidence Interval and 5\% error was in built in the formula.

\section{Results}

\section{Socio-demographic data of the samples}

We collected the demographic data of patients, like age, sex, cast, area, income, marital status, cousin marriages or not, we did not find any co-relation with these parameters and grading system or grading and abnormal p53 gene expression.

\section{Histopathological analysis}

According to the histopathological reports obtained from Fatima Memorial Hospital, 7 samples were of grade I, 10 of grade II and 13 of grade III. In our study there was not any grade 4 samples (Figure 3).

A- Sample No 19 grade III tumor under 10X

B- Sample No 20 grade III tumor under 10X

C- Sample No 22 grade III tumor under 10X

D- Sample No 23 grade III tumor under 10X

E- Sample No 13 grade II tumor under 10X

F- Sample No 17 grade II tumor under 10X

The grading was made by TNM grading system i.e. based on tumor, node involvement and metastatic spread, and representative reports on these tumor samples are shown in Figure 3.

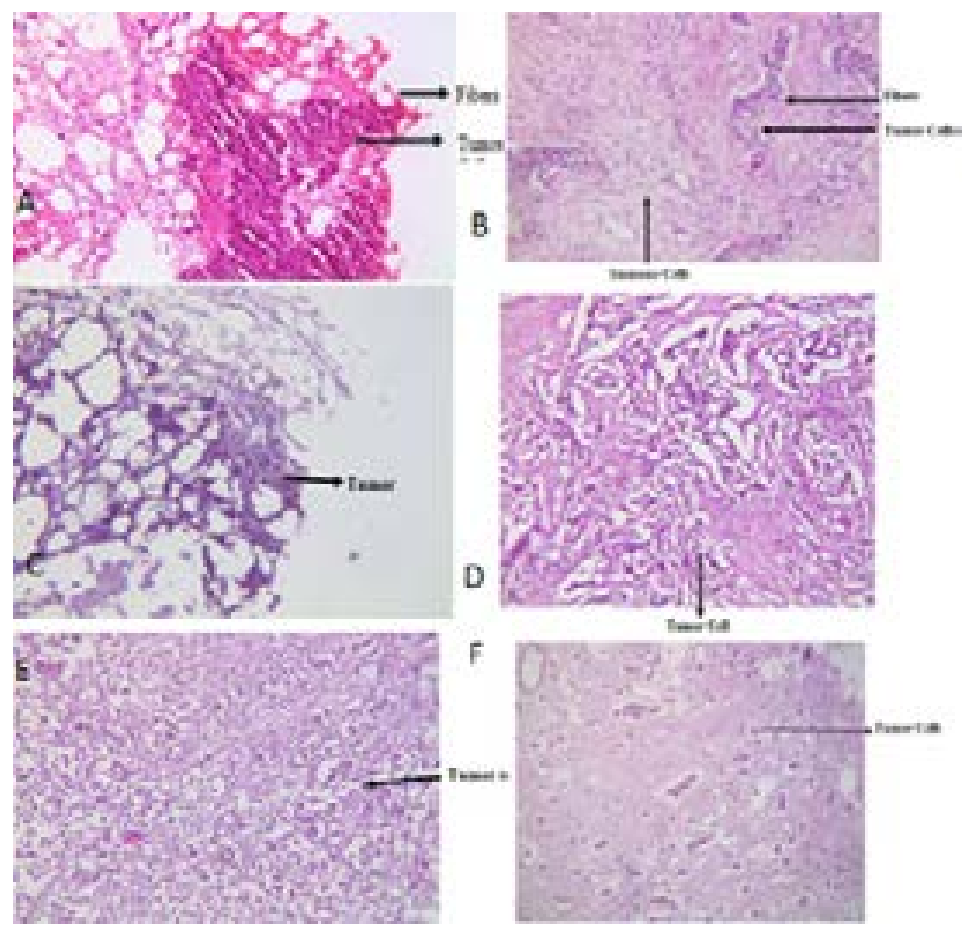

Figure 3: Representative pictures of some breast cancer sample 
The Nottingham histologic score is simply a scoring system to assess the grade of breast cancers. It is a total score based on 3 different sub-scores. The 3 sub scores were assigned based on 3 components of how the breast cancer cells look under a microscope. Each of the 3 features was assigned sub-score of 1,2, or 3 . 1 represent best, 2 represent moderate and 3 shows worst. Once the 3 sub-scores were added, a Nottingham score was obtained. The minimum score possible is $3(1+1+1)$ and the maximum possible is $9(3+3+3)$. The 3 components of Nottingham grading system are tubule formation, nuclear polymorphism and mitosis rate. If the tubule formation is more than $75 \%$, it scores $1,10-75 \%$ scores 2 and less than $10 \%$ scores 3 . The nuclear grade is score on the basis of similarity of the nucleus morphology of the cancer cells to normal cells. Most similar nucleus of the cancer cells to normal cell nucleus is score 1 and the most different one is score 3 . The mitosis rate of the cells is also scored on the basis that how much rapidly the cells grow. Slow cell division is score 1 and rapid cell division is score 3 . The mitosis rate of the tumor cell is count under 10 high power field (hpf) microscope.

Table 4. Histological Characteristics of Patients

\begin{tabular}{|c|c|c|c|c|c|c|}
\hline \multirow[t]{2}{*}{ Sample } & \multirow[t]{2}{*}{ No } & \multicolumn{2}{|c|}{ Grad } & \multirow[t]{2}{*}{ Necrosis } & \multirow[t]{2}{*}{ Desm } & \multirow[t]{2}{*}{ Inflam } \\
\hline & & Pleo & Mito & & & \\
\hline 19 & 3 & 3 & 1 & Not seen & Mild & No \\
\hline 20 & 3 & 2 & 2 & Seen & Moderate & Mild \\
\hline 22 & 3 & 3 & 2 & Not seen & Mild & Mild \\
\hline 23 & 3 & 2 & 2 & Not seen & Mild & No \\
\hline 13 & 3 & 2 & 1 & Not seen & Mild & Mild \\
\hline 17 & 2 & 2 & 1 & Not seen & Mild & Moderate \\
\hline
\end{tabular}

\section{Gene expression in grade I tumors}

Gene Expression of p53 gene in grade- 1 tumors was performed. The $\mathrm{Ct}$ values of each breast tumor were normalized with beta actin gene $\mathrm{Ct}$ values. The results were compared with normal breast sample and the 1 fold change was obtained for normal samples and the fold change above 1 showed the up-regulation and the fold change value below 1 was considered down-regulation. Out of 7 patients 5 showed up-regulation and 2 showed down regulations. All samples showed abnormal gene expression as compared to normal samples (Figure. 4).

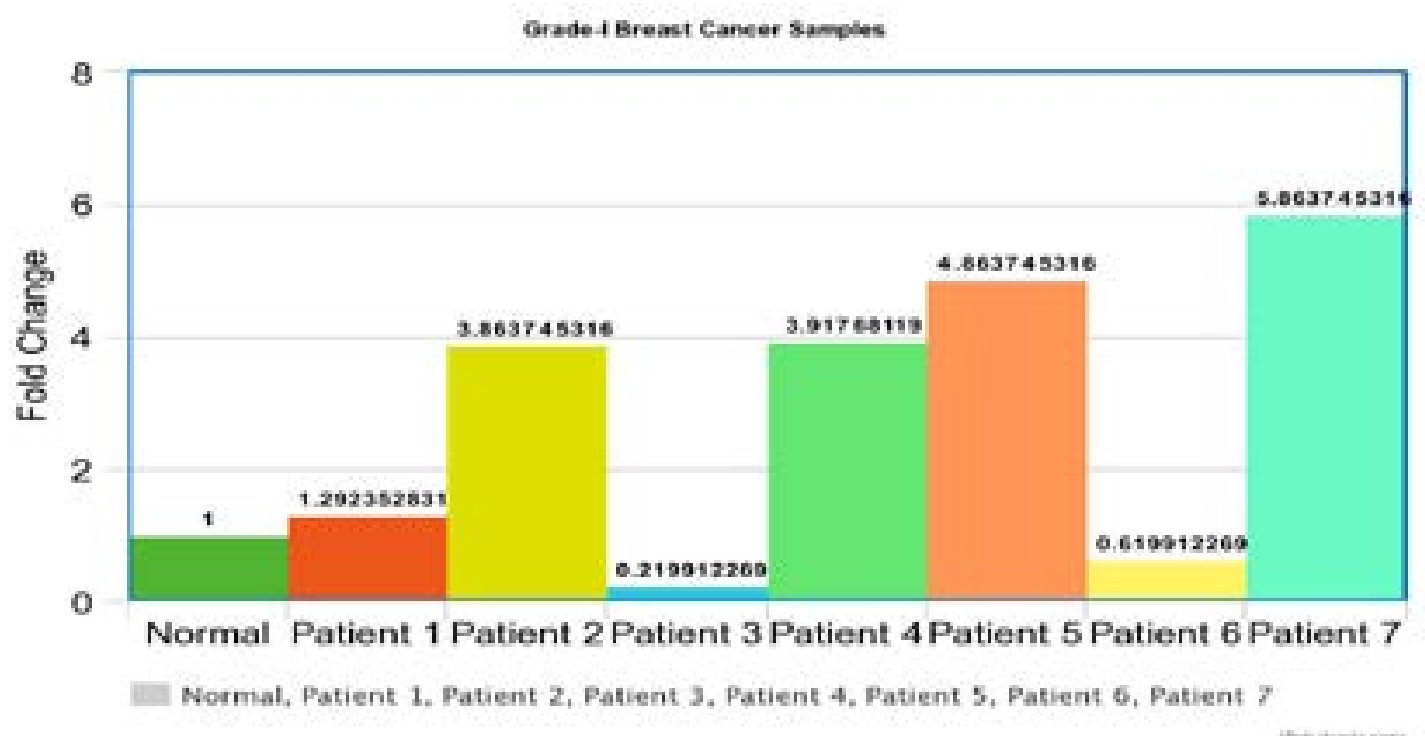

Figure 4. Gene expression of p53 gene in grade-1 tumors 


\section{Gene expression in grade II tumors}

Gene Expression of p53 gene in grade-2 tumors was performed. The Ct values of each breast tumor were normalized with beta-actin gene's Ct values. The results were compared with normal breast samples and the 1 fold change was obtained for normal samples and the fold change above 1 showed the up-regulation and the Ct value below 1 was considered down-regulation. Out of 10 patients 4 showed up-regulation and 6 showed down regulations. All samples showed abnormal gene expression as compared to normal samples (Figure 5).

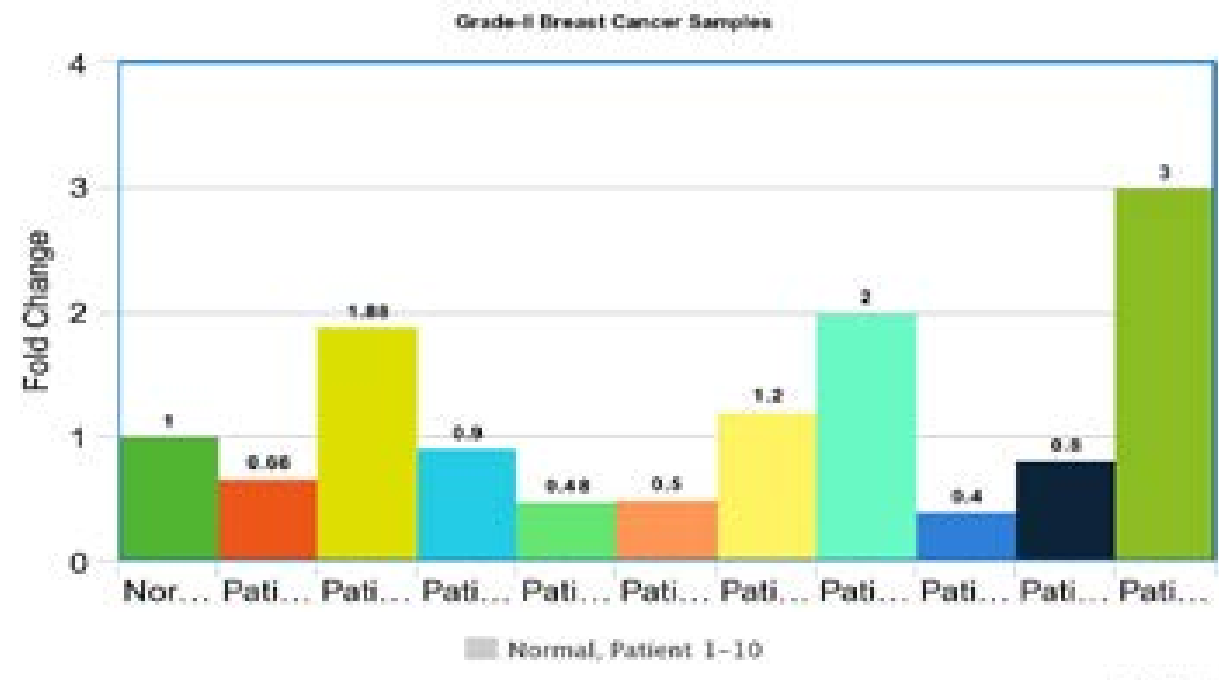

Figure 5. Gene expression of p53 in grade II tumors

Gene expression of p53 gene in grade III tumors Gene Expression of p53 gene in grade III tumors was performed. The $\mathrm{Ct}$ values of each breast tumor were normalized with beta-actin gene $\mathrm{Ct}$ values. The results were compared with normal breast sample and the 1 fold change was obtained for normal samples and the fold change above 1 showed the up-regulation and the Ct value below 1 was considered down-regulation. Out of 13 patients 10 showed up-regulation and 3 showed down regulations. All samples showed abnormal gene expression as compared to normal samples (Figure 6).

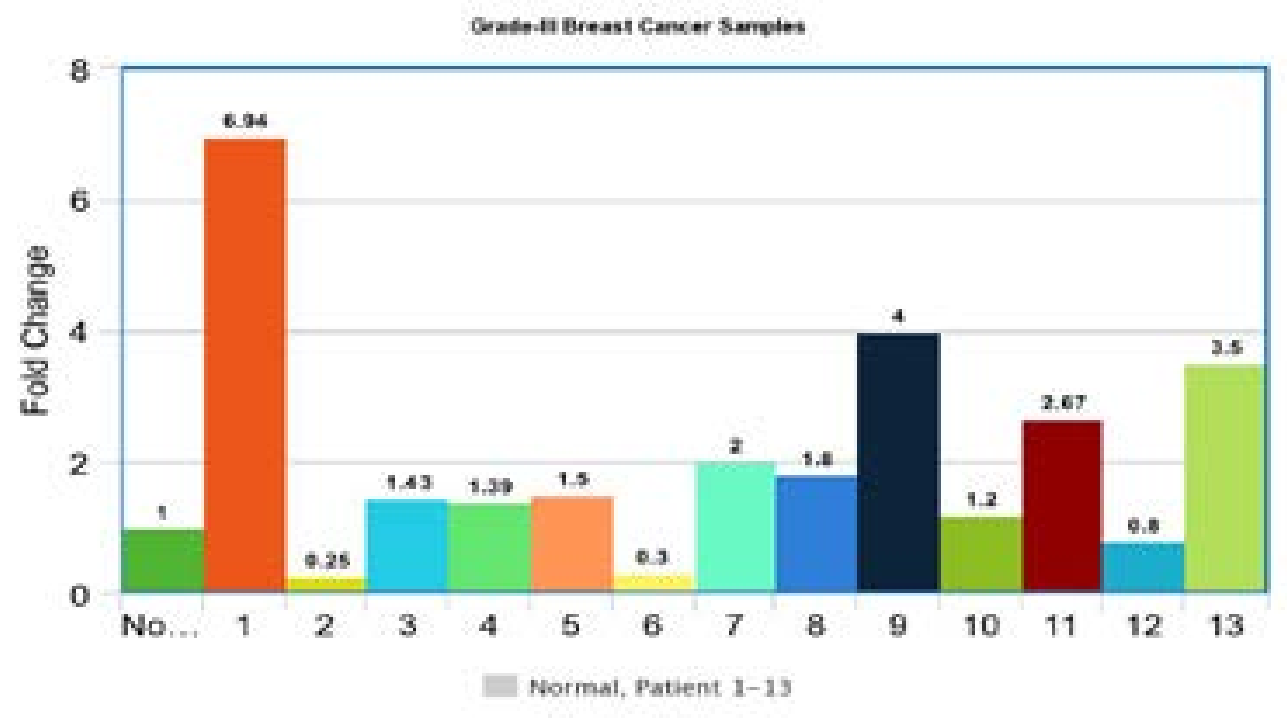

Figure 6. Gene expression of p53 gene in grade III tumors

Overall out of 30 samples 19 samples showed up regulation and 11 samples showed down regulation. Both types of results showed that p53 gene had some abnormal function in breast cancer and it has some. There was non-significant difference in fold change values of grade I, grade II and grade III, i.e. more than 0.05 $(>0.05)$, while if we see the total number of patients showing up regulation and down regulation then there was significant difference and up regulation was more than down regulation $(<0.0011)$, this is clear in Table 5 . 
Table 5. Fold change differences among grade I, II and III breast tumors.

\begin{tabular}{|c|c|c|c|c|}
\hline UP regulation & Down regulation & Grade 1 & Grade 2 & Grade 3 \\
\hline 1.3 & 0.22 & 1.3 & 0.7 & 7 \\
\hline 3.9 & 0.62 & 3.9 & 1.9 & 0.5 \\
\hline 4 & 0.7 & 0.22 & 0.1 & 1.43 \\
\hline 4.9 & 0.1 & 4 & 0.49 & 1.4 \\
\hline 5.9 & 0.49 & 4.9 & 5 & 1.5 \\
\hline 1.9 & 0.5 & 0.62 & 1.2 & 0.3 \\
\hline 1.2 & 0.4 & 5.9 & 2 & 2 \\
\hline 2 & 0.8 & & 0.4 & 1.8 \\
\hline 3 & 0.5 & & 0.8 & 4 \\
\hline 7 & 0.3 & & 3 & 1.2 \\
\hline 1.43 & 0.8 & & & 2.7 \\
\hline 1.4 & & & & 0.8 \\
\hline 1.5 & & & & 3.5 \\
\hline 2 & & \multicolumn{3}{|c|}{$>0.05$} \\
\hline 1.8 & & \multicolumn{3}{|c|}{ All grades differences } \\
\hline 4 & & & & \\
\hline 1.2 & & & & \\
\hline 2.7 & & & & \\
\hline 3.5 & & & & \\
\hline t-test & 0.001084601 & & & \\
\hline
\end{tabular}

\section{Discussion}

The current study is performed to investigate the expression profile of the $\mathrm{p} 53$ gene by using real-time PCR in different grades of breast cancer tissues, as previously no such study is documented. The present study concludes the abnormal gene expression of p53 in all grades of the breast tumors. Lukas reported that the molecular biology screening techniques are less in use for the determination of p53 expression as compared to the immunohistochemical analysis which is commonly done in ductal carcinoma in situ ${ }^{17}$. The present research findings showed that p53 is up-regulated and down-regulated in different grades of breast cancer and current results are in accordance with the several published studies which investigated the vital role of p53 gene in the carcinogenesis process of the breast tumors. It was reported by a study that around zero mutation was found in p53 in low-grade ductal carcinoma in situ (DCIS) and 30-40\% mutation in high grade ${ }^{15}$.
Shokouh study results showed p53 association in breast carcinoma subtypes with tumor grade and lymph node involvement.

The p53 mutation rates were found to be higher in high grade breast cancer and in younger age groups. While patients of; infiltrative ductal were $18.35 \%$, carcinoma in situ was in $26.5 \%$ of the patients and infiltrative lobular patients were $23.3 \%{ }^{18}$. Baumbusch et al, have done a study in 88 patients of breast cancer on mRNA expression of full-length $\mathrm{p} 53$ and its isoform $\Delta \mathrm{p} 53$ by using quantitative real-time PCR in both p53 mutant and wild type and to the clinical and biological data, its mRNA expression was related. The results provides the significant association with molecular subtypes and grade of in the upper or lower quartile of tumors with mRNA expression levels while the levels were significantly elevated of both isoforms mRNA levels in tumors with frame or missense mutation as compared to 
splice mutation in which significant levels reduced of mRNA to those with p53 expressing wild type ${ }^{19}$. Similarly, another study on breast cancer stages II and III was investigated in relation with gene expression profiling. The results of this research showed that compared to the normal breast tissue, the gene expression profiling is deregulated in the clinical stages of $\mathrm{II}$ and $\mathrm{III}^{20}$. Another study was conducted on breast cancer patients on over expression of $\mathrm{p} 53$ and its association was related to clinical pathological features of the breast cancers.

The results showed a significant correlation with the higher nuclear grade, larger tumors and disease-positive lymph nodes ${ }^{21}$. A study on the expression of p53 has demonstrated that an increased expression was significantly associated with increased tumor grade of invasive breast cancer $(p<0.006)$, lymphocytic infiltration $(\mathrm{p}<0.004)$ and lymphovascular invasion $(\mathrm{p}<0.003)$ while the p53 in low grade of ductal carcinoma in situ of all cases was negative, while in $2 / 3$ and all cases of intermediate grade and high grade it was positive 5. Archer et al determined the expression of p53 in advanced breast cancers and results have shown that the out of 92 patient's p53 were positive in $53(57.6 \%)$ patients having high stage tumors. In a current study most of the patients have grade II and III tumors. Similarly, study by Archer et al showed that grade wise distribution; $42.4 \%$ were of grade II and $54.3 \%$ were of grade III, which is correlated with high-grade tumors positive for $\mathrm{p} 53$ as $\mathrm{p}=0.08^{22}$ as compared to our study which includes all patient population uniformly. Another study suggested that p53 plays a crucial role as a tumor suppressor and also supports the results of the current investigation $^{23}$. Similarly a study conducted by Sekar also suggests the over expression of p53 is associated with high grades of breast cancer ${ }^{24}$. Saif et al conducted a study on Hspb1 and Tp53 Mutation and Expression Analysis in Cat Mammary Tumors While exons 3, 4 and 7 of Tp53 have a only single variation at c.105A>A/G, c. $465 \mathrm{~T}>\mathrm{T} / \mathrm{C}$ and c.859G $>\mathrm{T}$ respectively. The locus c.1050G $>\mathrm{G} / \mathrm{A}$ in exon 9 is a homozygous $(\mathrm{G})$ in 2 tumors and heterozygous $(\mathrm{G} / \mathrm{A})$ in other 3 samples. Sixty percent of cancers showed up-regulated trend of Tp53 gene. This study concludes that tumor specific mutations and ectopic expression of Tp53 genes may be useful in the diagnosis of the mammary lesions ${ }^{25}$.

The current study was used to investigate the p53 expression in humans by using real-time PCR in Pakistani population but for future the sample size should be increased for better understanding.

\section{Conclusion}

It is concluded from the present study that p53 gene may be correlated as a diagnostic marker of breast cancer as the loss of its normal function can leads toward the breast cancer progression and its over expression associated with breast cancer however large sample size is required for better understanding. The abnormal expression of $\mathrm{p} 53$ shows that there are some genetic and epigenetic factors which are the primal cause of an abnormal gene expression. It is recommended that perform next generation sequencing (NGS) of the gene to find out the mutations causing the abnormal behavior of p53 gene.

\section{Acknowledgements}

The authors acknowledge to administration of Jinnah Hospital, Lahore, Services Hospital Lahore, and Mayo Hospital Lahore for helping in collection of breast cancer tissues and Higher Education Commission for the grant No: 21-664SRGP/R\&D/HEC/2015.

\section{Conflicts of interest}

There is no conflict of interest among the authors.

\section{References}

1. Stratton MR, Campbell PJ, Futreal PA. The cancer genome. Nature. 2018; 458: 719-724.

2. Ataollahi MR, Sharifi J, Paknahad MR, Paknahad A. Breast cancer and associated factors: a review. $J$ Med Life. 2015; 8: 6-11.

3. Akbar M, Akbar K, Naveed D. Frequency and correlation of molecular subtypes of breast cancer with clinicopathological features. J Ayub Med Coll Abbottabad 2014; 26(3): 290-3.

4. Amjad A, Khan IK, Kausar Z, Saeed F, Azhar L. Anwar, P. Risk factors in breast cancer progression and current advances in therapeutic approaches to knockdown breast cancer. Clin Med Biochem 2018; 4: 1.

5. Muhammad EMS, Ahmad A N, Guirguis $\mathrm{MN}$, Ali AM. Immunohistochemical p53 expression in breast carcinoma with correlation to clinico-pathological parameters. Med. J. Cairo Univ 2012; 80(2): 179-89.

6. Menhas R, Umer S. Breast cancer among Pakistani women. Iran J Public Health 2015; 44(4): 586-7.

7. Bansal C, Pujani M, Sharma KL, Srivastava AN, Singh US. Grading systems in the cytological diagnosis of breast cancer: a review. J Cancer Res Ther 2014: 10(4), 839-45.

8. Usman A, Ali A, Lakhanna NK, Zafar H. Frequency of benign and malignant breast lesions: a histopathological analysis. Isra Medical Journal 2016; 8(3): 138-40.

9. Mohapatra M, Satyanarayana S. Evaluation of 
clinico: Pathologic findings of breast carcinoma in a general hospital in Southern India. Indian J Cancer 2013; 50(4), 297-301.

10. Pervaiz, R. Genetic mutations associated with breast cancer in Pakistan. Malaysian Journal of Medical and Biological Research 2015; 2(3): 308-13.

11. Sharma S, Sambyal V, Guleria K, Manjari M, Sudan M, Uppal MS. Tp53 polymorphisms in sporadic north indian breast cancer patients. Asian Pac J Cancer Prev. 2014; 15(16), 6871-9.

12. Gasco M, Shami S, Crook T. The p53 pathway in breast cancer. Breast Cancer Res. 2002; 4: 70-6.

13. Mitas M, Mikhitarian K, Walters C, Baron PL, Elliott BM, Brothers TE. Quantitative real-time RTPCR detection of breast cancer micrometastasis using a multigene marker panel. Int J Cancer. 2001; 93(2), 16271.

14. Bernard PS, Wittwer CT. Real-time PCR technology for cancer diagnostics. Clin Chem 2002; 48(8), 1178-85.

15. Al-Joudi, FS, Iskandar ZA, Rusli J. The expression of p53 in invasive ductal carcinoma of the breast: a study in the North-East States of Malaysia. Med J Malaysia. 2008; 63(2): 96-9.

16. Livak KJ, Schmittgen TD. Analysis of relative gene expression data using real-time quantitative PCR and the 2- $\Delta \Delta$ CT method. Methods 2001; 25(4): 402-8. 17. Lukas J, Niu N, Press MF. P53 mutations and expression in breast carcinoma in situ. Am J Pathol 2002; 156(1): 183-91.

18. Shokouh TZ, Ezatollah A, Barand P. Interrelationships between Ki67, HER2/neu, p53, ER, and PR status and their associations with tumor grade and lymph node involvement in breast carcinoma subtypes: retrospective-observational analytical study. Medicine (Baltimore) 2015; 94(32): e1359.

19. Baumbusch LO, Myhre S, Langerod A, Bergamaschi A et al. Expression of full-length p53 and its isoform $\Delta \mathrm{p} 53$ in breast carcinomas in relation to mutation status and clinical parameters. Mol Cancer 2006; 5: 47.

20. Folgueira MA, Brentani $\mathrm{H}$, Katayama ML et al. Gene expression profiling of clinical stages II and III breast cancer. BrazJ Med Biol Res 2006; 39(8): 1101-13. 21. Kikuchi S, Nishimura R, Osako T et al. Definition of p53 overexpression and its association with the clinicopathological features in luminal/HER2-negative breast cancer. Anticancer Research 2013; 33(9): 3891-7.

22. Archer, S. G.; Eliopoulos, A.; Spandidos, D.; Barnes, D.; Ellis, I. O.; Blamey, R. W., et al. Expression of ras p21, p53 and c-erbB-2 in advanced breast cancer and response to first line hormonal therapy. British Journal of Cancer. 1995, 72, 1259.

23. Constantinou C, Papadopoulos S, Karyda E, Alexopoulos A, Agnanti N, Batistatou A. Expression and Clinical Significance of Claudin-7, PDL-1, PTEN, c-Kit, c-Met, c-Myc, ALK, CK5/6, CK17, p53, EGFR, Ki67, p63 in Triple-negative Breast Cancer-A Single Centre Prospective Observational Study. In vivo 2018; 32(2), 303-11.

24. Sekar P, Bharti JN, Nigam JS, Sharma A, Soni PB. Evaluation of p53, HoxD10, and E-cadherin status in breast cancer and correlation with histological grade and other prognostic factors. Journal of Oncology 2014; $1-4$.

25. Saif R, Awan AR, Lyons L, Gandolfi B, Tayyab M, Babar ME, Mehmood AK, Ullah Z, Wasim M. Hspb1 and Tp53 mutation and expression analysis in cat mammary tumors. Iran J Biotechnol 2016;14(3):202. 